\title{
Assessing Adequacy of Retirement Income for U.S. Households: A Replacement Ratio Approach
}

\author{
Yoonkyung Yuh \\ Ewha School of Business, Ewha Womans University, Ewha Shinsegae Building RM425, 11-1 \\ Daehyun-dong, Seodaemun-gu, Seoul 120-750, Republic of Korea (ROK). \\ E-mail: yuhyk@ewha.ac.kr
}

The retirement income replacement ratio is projected using the Federal Reserve's Survey of Consumer Finances. On the basis of lognormal portfolio projections and current portfolio allocation, at least 44 per cent of pre-retired households will not be able to maintain 70 per cent of permanent income standard in retirement. Households planning to retire later and taking a high financial risk in savings and investments have a higher projected replacement ratio. Households having a high proportion of non-housing assets held in equity or bonds have a higher projected replacement ratio than those having a high proportion in cash equivalents.

The Geneva Papers (2011) 36, 304-323. doi:10.1057/gpp.2011.7;

published online 2 March 2011

Keywords: replacement ratio; retirement planning; retirement income adequacy; lognormal forecasting model

\section{Introduction}

Financial planning for retirement has become a major concern for many Americans given the rapidly ageing working population and the expectation that Social Security faces financial insolvency. Attaining a financially secure retirement is an important goal both for American workers and policy-makers since financial insecurity among a large retirement cohort can place a heavy financial burden on society. Planned reduction in Social Security benefits for retirement before the age of 67 years and the shifting away from defined benefit pension plans increase the importance of personal savings as a source of retirement income and places more responsibility of retirement planning upon the individual. Over the last quarter of a century, the type of pension has shifted from defined-benefit plans, where workers receive a life annuity based on years of service and final salary, to $401(\mathrm{k})$ plans, where individuals are responsible for their own savings. ${ }^{1}$ In other words, asset allocation decisions within the retirement savings programmes are important for individual investors given the increase in $401(\mathrm{k})$ and related retirement savings programmes and the decrease in defined-benefit plans since the $1980 \mathrm{~s}^{2}$ In the near future, these trends could lead to an income shortfall for those older Americans who do not save adequately for retirement or postpone retirement. ${ }^{3}$

\footnotetext{
${ }^{1}$ Munnell et al. (2007).

${ }^{2}$ Yang and Huang (2009), Blake et al. (2007).

3 apRoberts (2009).
} 
Thus, individuals must carefully determine how much to save for retirement and how to invest in savings in order to be prepared financially for retirement.

The issue of a secure retirement has been analysed in previous studies with a focus on whether pre-retired people will have adequate retirement income. Typically, these studies have assessed the retirement income adequacy by comparing retirement income with pre-retirement income using a specified rate to be replaced. That is, the retirement income adequacy may be defined as a constant nominal level of consumption during retirement as in during the working years, and this is called the "retirement income replacement ratio". Typical target rates vary from 65 to 85 per cent depending on the household income and marital status. ${ }^{4}$ This measure assumes that consumption needs are expected to decline during retirement since retirees do not pay payroll taxes, they no longer need to save for retirement, their mortgage is generally paid off, and they no longer have work-related expenses. However, there is a long-standing debate on whether retirees must spend more or less than younger workers to achieve a similar level of living. Some authors have interpreted the decline in consumption at the onset of retirement as being evidenced by some households not planning sufficiently for retirement. ${ }^{5}$ Therefore, the reduced consumption of retired households presented in many studies may not fully reflect their desired (planned) level of living in retirement because it is not clear whether their lower consumption level is caused by their preferences or by reduced categories in expenses or by inadequate retirement savings.

An important issue when calculating replacement ratios is how to define the preretirement income used in the denominator. A final income in the year prior to retirement or permanent income is often used to define the pre-retirement income. The final income just before retirement is used when assuming that people are interested in replacing the earnings they enjoy immediately prior to retirement. On the other hand, permanent income is used when assuming that people are interested in replacing lifetime income, and this approach is based on a "consumption smoothing" assumption of the life cycle model. The consumption smoothing is defined as the constant marginal utility of consumption over the life cycle; thus, the permanent income is regarded as the "optimal" or "desired" consumption over the life cycle. Several researchers argue that it is more appropriate to define earnings based on the actual patterns of work across a lifetime. ${ }^{6}$ That is, individuals, in effect, must pay for their retirement with wages earned over their lifetimes and not just in the peak of their careers.

From a theoretical economic perspective, the replacement ratio approach is less appealing than a life cycle-dynamic programming approach, as it ignores utility theory and behavioural responses to uncertainty. However, the replacement ratio is a measure that is more robust and less subjected to distortion by the differences in modelling approaches. ${ }^{7}$ It is also a popular model among retirement planning practitioners and

\footnotetext{
${ }^{4}$ Munnell et al. (2007), Wolff (2006), Booth (2004), Aon (2001).

${ }^{5}$ Bernheim et al. (2001).

${ }^{6}$ Smith (2003), Boskin and Shoven (1987).

${ }^{7}$ Valdez and Chernih (2003).
} 
can be seen as a relatively tractable approximation to the life cycle model ${ }^{8}$ On the basis of the consumption smoothing of the life cycle model and suggestions by previous studies, ${ }^{6}$ this study defines the adequacy of retirement income as accumulating enough wealth to maintain a permanent income level of living in retirement. The permanent income as a benchmark for evaluating the retirement income adequacy has been ignored in previous studies because the variable is not directly available from the data and it is often difficult to estimate precisely. Using the permanent income of individual households, this study projects the retirement income replacement ratios to evaluate their income adequacy for retirement. Furthermore, by focusing on retirement planning variables, the current study investigates the determinants of the projected replacement ratio of individual households as an indicator of retirement income adequacy. The unique contributions of this research are the use of household-specific information on permanent income, planned retirement age and asset allocation, projection of retirement wealth using asset specific growth rates, and inclusion of equity, bond and cash shares as explanatory variables for the replacement ratio. Therefore, results of this study could provide some directions for planning for achieving sufficient retirement income.

\section{Previous literature}

Assessing the adequacy of retirement income involves determining what is available and what is needed for retirement. The most commonly used method to estimate the consumption needs in retirement is to specify the percentages of pre-retirement income necessary to maintain a constant level of living throughout the retirement years. Using this replacement ratio approach, many previous studies have evaluated the ratio of household income needed to finance the desired retirement consumption relative to pre-retirement income.

Bernheim's "Baby Boomer Retirement Index" is the ratio of actual level of older persons' accumulated financial and housing savings and the simulated target level of savings minus Social Security and pension savings. According to the index, baby boomers in 1997 saved 38.5 per cent of what they needed to maintain their current standard of living after 65 years. Mitchell and Moore ${ }^{10}$ examined the adequacy of asset holdings among people on the verge of retirement using the Health and Retirement Study (HRS). Seventy per cent of the households' current earnings are taken to be the amount necessary to maintain pre-retirement household consumption into the retirement years. They found that households have on average between 75 and 88 per cent of what is needed when retiring at the age of 65 years in 1992. Engen et $a l .{ }^{11}$ developed a stochastic life cycle model, in which adequacy is defined as the wealth accumulation sufficient to enable the smoothing of the marginal utility of consumption over the life cycle. The authors found that 60.5 per cent for the HRS and

\footnotetext{
${ }^{8}$ Moore and Mitchell (2000).

${ }^{9}$ Bernheim (1997).

${ }^{10}$ Mitchell and Moore (1998).

${ }^{11}$ Engen et al. (2000).
} 
66 per cent for the Survey of Consumer Finances (SCF) of households have ratios of broad wealth to earnings that exceed the median simulated wealth-earnings ratio for households with the same observable characteristics. Their replacement ratio for the median household is 72 per cent, leading the authors to conclude that households are close to being adequately prepared for retirement. Scholz et al. ${ }^{12}$ constructed a stochastic life cycle model that reflects uncertainty regarding life expectancy, the uninsurability of certain future income and expense flows, and the characteristics of tax, transfer, social and private pension arrangements. From the HRS, they found that 84.4 per cent of the households reach this optimal wealth level and concluded that Americans are saving enough to maintain living standards in retirement.

These studies that used a simulation model to find an optimal target develop a rigorous approach for assessing the adequacy of savings. However, they use some strong and uniform assumptions in the model specifications on the rate of return, wage growth rate, asset allocations and retirement age among others. ${ }^{13}$ Therefore, risk or uncertainty factors in asset growth and household-specific factors in asset allocations, earning growth and retirement age are not taken into account in their model. Some studies derived optimal distributions of wealth only for representative households. Thus, their model does not allow for variations in each household. In addition, some studies substantially understate the extent of retirement income adequacy since they do not include single-person households that have been shown in previous studies to be more at risk than married couples ${ }^{11}$ and Social Security and pension assets from the available income for retirement. ${ }^{9}$

Using the HRS, Gustman and Steinmeier ${ }^{14}$ estimated the annuitised value of the wealth of households of 51-61 year olds as on the date of expected retirement. They found that wealth accumulated to date by the HRS population is sufficient to finance a nominal annuity generating a replacement rate averaging of 86 per cent of the final earnings. Butrica et al. ${ }^{15}$ used projections of retirement income to compare the economic wellbeing of retirees in the baby boom generation with current retirees using the Social Security Administration's Model of Income in the Near Term data system. Their study found that median replacement rates are projected to be 93 per cent for current retirees, and the replacement rates are expected to decrease to about 80 per cent for future cohorts of retirees. Wolff ${ }^{16}$ used the SCF to study savings adequacy over time for various groups of households nearing retirement between the ages of 47 and 64 years. He found that 43 per cent of households can replace less than half of their pre-retirement income during retirement in 1998. He also discovered that in 2001, only 53.4 per cent of all households in the age group of 47-64 years are expected to have replacement rates of more than 50 per cent. Haveman et al. ${ }^{17}$ examined wealth and the measures of adequacy using the New Beneficiary Survey sample of individuals who first received the Social Security retired-worker benefits in

\footnotetext{
${ }^{12}$ Scholz et al. (2006).

${ }^{13}$ Bernheim (1997), Moore and Mitchell (2000), Scholz et al. (2006).

14 Gustman and Steinmeier (1998).

${ }^{15}$ Butrica et al. (2003).

${ }^{16}$ Wolff $(2002,2006)$.

${ }^{17}$ Haveman et al. (2007).
} 
1980-1981. They found that about half of the new retirees have insufficient resources to enable the full maintenance of estimated pre-retirement consumption in retirement, and about 40 per cent fail to meet the " 0.7 of permanent pre-retirement earnings" standard used in many studies.

However, most of these studies have used "expenditure" instead of "consumption" or "final earning" instead of "permanent income" to measure the pre-retirement living standard. Aguiar and Hurst ${ }^{18}$ found that consumption is stable during retirement and suggested that expenditure may be a generally more misleading measure of consumption. Furthermore, the above studies that used a specified replacement ratio tend to overstate or understate the extent of the adequacy for several reasons. For example, some studies do not include any additional savings to be accrued between current age and the age of retirement ${ }^{19}$ and do not include the positive return to real assets and continued accrual of pension value that will accrue before retirement. ${ }^{14}$ In addition, for projecting or annuitising the accumulated retirement wealth, a uniform assumption on the rate of return such as 3 per cent ${ }^{16}$ or 2.75 per cent ${ }^{17}$ are used regardless of asset allocations for each household. Wolff used current earnings as the denominator to calculate the replacement ratio, while Haveman et al. assumed that all wealth is annuitised, assuming that couples require 1.66 of the income of a single individual to maintain equivalent consumption.

In sum, the previous studies take a variety of assumptions and procedures in the issue of the adequacy and provide a wide range of conclusions on it. They also use varying measures of available resources and needs in retirement. Generally, the quite disparate conclusions the studies present are closely tied to the denominator for the replacement ratio used and to the assumptions made regarding the treatment of resources.

\section{Model}

\section{Simple life cycle model}

The standard model for analysing savings behaviour is the life cycle model of consumption and savings, which is also known as the "life cycle hypothesis". ${ }^{20}$ The central tenet of the life cycle model is that agents attempt to keep the marginal utility of the consumption constant across predictable income changes such as retirement, and it emphasises consumption smoothing throughout the life cycle. According to the model, the optimal growth of consumption from year $n$ to year $n+1$ to maximise lifetime utility under certain conditions (e.g., constant relative risk aversion) is derived as

$$
\frac{C_{n+1}}{C_{n}}=\left(\frac{1+r}{1+\rho}\right)^{-1 / \varepsilon} .
$$

This equation shows that the future consumption increment depends on real rate of return $(r)$, personal discount rate $(\rho)$ and the risk aversion factor $(\varepsilon)$. If $r=\rho$, the

\footnotetext{
${ }^{18}$ Aguiar and Hurst (2005).

${ }^{19}$ Gustman and Steinmeier (1998), Wolff (2002, 2006).

${ }^{20}$ Modigliani and Brumberg (1954).
} 
consumption holds constant over time. This assumption has been used in some previous studies. ${ }^{21}$ The model argues that households would have the goal of having the same consumption each year, and assuming a constant real income before retirement, a household should save the same percentage of income each year and should accumulate enough investment assets to maintain the same consumption in retirement, as it could have before retirement. Thus, the life cycle model implies a "consumption smoothing" pattern in that the consumption amount remains relatively stable despite changes in current income. There are many complexities in applying the life cycle model to the analysis of the adequacy of retirement savings, but the standard approach is the one used by Engen et al.," who noted that "A household that is saving adequately is defined as one that is accumulating enough wealth to be able to smooth its marginal utility of consumption over time".

\section{Projected retirement income replacement ratio}

Generally, retirement wealth can be defined as adequate, if the total retirement income is equal to or greater than the total desired retirement consumption level. ${ }^{22}$ Information on the pre-retirement standard of living can be used to estimate the desired retirement level of living, assuming that consumption is quite stable during retirement $^{18}$ and that individuals would like the same consumption level after retirement as before retirement (Scholz et al., ${ }^{12}$ etc.). Thus, based on previous studies and consumption smoothing from the life cycle model, the current study estimates the retirement income replacement ratio of individual households based on their projected retirement wealth and permanent income. This study assumes that households seek to maintain a constant level of consumption in real terms and therefore purchase an inflation-protected annuity upon retirement. That is, all the values in the model are assumed in real terms, accounting for the inflation effect. Then, the permanent income of each household is compared with the income that can be generated by converting their retirement wealth into this hypothetical annuity, which is a periodic stream of income that lasts for life. Thus, the projected retirement income replacement rate $(P R)$ is derived as

$$
P R=\frac{R I}{P I}
$$

where $R I$ is annuitised retirement income from total retirement wealth; and $P I$ is permanent income.

Since $P R$ captures the amount of retirement income financed by the households' retirement wealth relative to their permanent income, it measures the extent of the adequacy of retirement income for each individual household. The withdrawal from accumulated retirement wealth is treated as buying a fixed income annuity with annual constant payment, assuming a fixed amount withdrawal during retirement. Therefore,

\footnotetext{
${ }^{21}$ Engen et al. (2000), Scholz et al. (2006).

${ }^{22}$ Hatcher (1998).
} 
the retirement income from the projected total retirement wealth $(R I)$ can be estimated as follows:

$$
R I=\frac{T W}{P V I F A} \times(1+r)
$$

where $T W$ is projected total retirement wealth; $P V I F A=\left\{1-1 /(1+\mathrm{r})^{\mathrm{D}-\mathrm{R}}\right\} / r$ and is present value interest factor for an annuity; $r$ is real return by corresponding investment categories of retirement portfolio; $D$ is age of death; and $R$ is planned retirement age.

The projected total retirement wealth $(T W)$ can be sated as follows:

$$
T W=\mathrm{DBW}+\mathrm{DCW}+\mathrm{SSW}+\mathrm{FW}+\mathrm{NFW},
$$

where DBW is defined benefit wealth; DCW is defined contribution wealth; SSW is Social Security wealth; FW is financial wealth; and NFW is non-financial wealth.

The projected replacement rate for each wealth component $\left(P R W_{i}\right)$ is calculated as follows:

$$
P R W_{i}=\frac{R I W_{i}}{P I}
$$

where $R I W_{i}$ is annuitised retirement income from each wealth component $(i=1$ for DBW, 2 for DCW, 3 for SSW, 4 for FW, and 5 for NFW, respectively).

$P R W_{i}$ captures the proportion of each wealth component to replace the permanent income; thus, it measures the extent of retirement income adequacy from each wealth composing total retirement wealth.

\section{Methodology}

To operationalise the empirical model, retirement wealth needs to be clearly defined, and the methods for projecting the levels of retirement wealth must be selected.

\section{Data and sample}

The data analysed in this study is from the Federal Reserve's most recent 2004 SCF. Both the SCF and HRS are frequently used data in this area. While the SCF includes households of all ages, the HRS covers a specific group of households aged 51-61 years in 1992. Thus, the HRS having a relatively older sample than the SCF cannot reflect the impact of increasing longevity and a contracting retirement income system. ${ }^{1}$

The SCF is a triennial survey sponsored by the Board of Governors of the United States Federal Reserve System with the cooperation of the U.S. Department of Treasury. Its purpose is to provide comprehensive, detailed information on the financial characteristics of the U.S. households. The cross-sectional SCF data set is more than adequate for the purpose of providing a representative benchmark of retirement account accumulations. The sample of this study is comprised of 
households currently working and with a head of household aged 35-70 years. Since this study aims to project the retirement income replacement ratio of future retirees, the sample only includes households with either a head or spouse currently working. Respondents who are younger than 35 years might change jobs or marital status; therefore, the sample includes only those over 35 years. In addition, the $70-\frac{1}{2}$ mandatory Social Security withdrawal age is used to select those under the age of 70 years.

\section{Permanent income}

Permanent income can be generally regarded as an "optimal" level of consumption, and it is used as a proxy for the desired level of living over a lifetime. ${ }^{18}$ Therefore, this study considers that the permanent income of individual households represents their desired (planned) consumption level over the life cycle. Since a direct measure about the permanent income is not available in the SCF, normal income which is directly available from the data is used as a proxy. The normal income in the SCF eliminating transitory variations in the current income provides a good approximation for the permanent income ${ }^{23}$ and it has been used in previous studies.

\section{Empirical definition of retirement wealth}

Retirement wealth is defined to include retirement income from defined contribution (DC) and defined benefit plans, Social Security, financial assets and non-financial assets.

\section{Defined benefit wealth and defined contribution wealth}

The SCF data set has variables recording the expected age of taking defined benefit pension, payment, and the frequency of payment for the respondent and spouse, respectively. This study defines the amount of defined benefit pension as the product of payment and frequency of payment. The DBW at retirement is estimated using an appropriate discount rate. The $50^{\text {th }}$ percentile rate of return for corporate bonds from lognormal projection is used as the discount rate for calculating the DBW. ${ }^{24}$ The DCW is projected based on the assumption of constant annual contribution. ${ }^{10}$ It is also assumed that workers remain in their company until retirement, and the term is equivalent to the DC contract, thus asset allocations in the DC plans is also assumed to be constant. Current balance and contributions to the DC accounts are classified into four groups including cash equivalents, bonds, stocks and real estates. Then, the DCW is projected according to the corresponding asset categories.

\footnotetext{
${ }^{23}$ Kennickell (1995).

${ }^{24}$ Yuh et al. (1998).
} 


\section{Social Security wealth}

This study estimates the annual Social Security benefit using permanent income, planned retirement age and marital status which are provided by the SCF. It is assumed that the current Social Security rules remain in effect indefinitely. The Social Security projection requires the average indexed monthly earnings (AIME) since a person's Primary Insurance Amount (PIA) is derived from it. The permanent income is used as a proxy of AIME in this study, and the person's PIA is derived from this AIME based on the existing rules. ${ }^{25}$ For married couples, separate imputations are performed for the husband and wife, and an adjustment in the benefits is made for the surviving spouse. The estimated Social Security benefit is adjusted for early or delayed retirement as indicated by the planned retirement age, and a spouse's benefit equalling to 50 per cent of the pension of the higher paid spouse is also applied for married couples. The present value of the SSW at the point of planned retirement is then estimated. The discount rate for the present value is calculated based on the $50^{\text {th }}$ percentile return for corporate bonds from the lognormal projection as the calculation of the DBW. ${ }^{24}$

\section{Financial wealth and non-financial wealth}

FW includes financial assets such as checking, savings, stock and mutual funds. These are also classified into cash equivalents, bonds and stocks to estimate the FW at retirement. The value of all other real estates, except housing, and owned business is counted as NFW. Whether or not to include the house as a retirement asset is quite controversial in the literature, although it is a key component of savings for many Americans on the verge of retirement. Some studies have reported that retirees do not downsize their homes at retirement nor do they take up reverse mortgages, ${ }^{26}$ and they do not want to consume home equity to finance retirement. ${ }^{11}$ Lusardi and Mitchell ${ }^{27}$ found that 60 per cent of homeowners aged 50 to 70 years do not plan to sell their homes to finance retirement, while about 70 per cent feel that there is a minimal (10 per cent or less) chance they would sell their homes to pay for retirement. Therefore, most elderly and pre-retired people do not plan to sell their house to finance additional retirement expenses. In addition, there is a concern about reliance on housing values to finance retirement since a sharp interest rate increase can induce a "hard landing" in housing values. ${ }^{27}$ Thus, this study excludes the housing in estimating the NFW. In the FW and NFW, the proportions invested in cash equivalents, bonds, stocks, business assets and real estate are assumed to be constant until retirement.

\section{Retirement period}

The retirement period is determined as the difference between an individual's expected age at death and age at planned retirement. Expected age at death is estimated by

\footnotetext{
25 Social Security Administration (2005).

${ }^{26}$ Venti and Wise (1990, 1991).

${ }^{27}$ Lusardi and Mitchell (2007).
} 
gender and marital status using the Actuarial Annuity tables published by the Internal Revenue Services. Original single life annuities are used for single people, while ordinary joint life and survivor annuities are used for married couples. ${ }^{28}$

\section{Projection of future rates of return}

To determine the level of retirement wealth at the planned retirement age, the value of current assets must be projected forward, and this requires information on the future rates of return for these assets. The total wealth available for retirement from DC plans, financial assets and non-financial assets is projected using future real rates of return for the corresponding asset category. Future real rates of return are projected separately for stocks, bonds, cash equivalents, business assets and real estate assets based on a lognormal forecasting model with historical rates of return data. ${ }^{29}$ In the lognormal forecasting model, the natural logarithms of asset return relatives (i.e., one plus total return) are assumed to be normally distributed. If $E_{1}$ and $V_{1}$ are the mean and variance of the asset return relatives $\left(e^{r}=1+r_{e}\right)$ for one year, then the mean and variance of the asset return relatives over $t$ years are $E_{t}=E_{1}^{t}$ and $V_{t}=\left(V_{t}-E_{1}^{2}\right)^{t}-E_{1}^{2 t}$, respectively. Thus, the mean and variance do not increase proportionately with time under the lognormal distribution assumption. ${ }^{30}$ In addition, since the lognormal distribution is skewed to the right, the expected value, or mean, is greater than the median. In addition, unlike the normal model, the lognormal forecasting model does not project negative values and may produce more plausible and accurate predictions for market returns. ${ }^{31}$ Furthermore, it is straightforward to form probabilistic forecasts of both compound rates of return and wealth values at the ending period. Considering these advantages of the lognormal model compared with models using normal distribution, this study used the lognormal forecasting model to project growth rates for separate asset categories. Under this model, wealth at time $n$ (assuming reinvestment of all income is non-taxable) is

$$
\begin{aligned}
\operatorname{Ln}\left(W_{n}\right)= & \operatorname{Ln}\left(W_{0}\right)+\operatorname{Ln}\left(1+r_{1}\right) \\
& +\operatorname{Ln}\left(1+r_{2}\right)+\cdots+\operatorname{Ln}\left(1+r_{n}\right),
\end{aligned}
$$

where $W_{n}$ is the wealth value at time $n ; W_{0}$ is the initial investment at time $0 ; r_{1}$, $r_{2}, \ldots, r_{n}$ is the total returns on the portfolio for the rebalancing period ending at times $1,2, \ldots, n$.

The geometric mean return over the same period, $r_{G}$, is

$$
r_{G}=\left(\frac{W_{n}}{W_{0}}\right)^{n^{-1}}-1,
$$

where $r_{G}$ is the geometric mean return; and $n$ is the inclusive number of periods.

\footnotetext{
${ }^{28}$ Internal Revenue Services (2003).

${ }^{29}$ Ibbotson Associates (2005).

${ }^{30}$ Thorley (1995).

${ }^{31}$ Crow and Shimizu (1988), Ibbotson Associates (2005).
} 
Table 1 Projected rates of return by lognormal forecasting model

\begin{tabular}{lccr}
\hline Asset category & $m_{i}$ & $s_{i}$ & $R_{i}$ \\
\hline Large stock & 0.0706 & 0.1853 & 0.0731 \\
Small stock & 0.0926 & 0.2795 & 0.0970 \\
Corporate bond & 0.0275 & 0.0943 & 0.0279 \\
Intermediate-term government bond & 0.0222 & 0.0673 & 0.0225 \\
Treasury bill & 0.0066 & 0.0398 & 0.0066 \\
\hline
\end{tabular}

Note: $R_{i}$ is estimated rate of return for the $50^{\text {th }}$ percentile of each asset based on data from Ibbotson Associates (2005), and $m_{i}$ and $s_{i}$ are defined in Eq. 9.

In the lognormal forecasting model, the expected value $(m)$ and standard deviation $(s)$ of the natural logarithm of the return relative of the portfolio can be calculated from the expected return $(\mu)$ and standard deviation $(\sigma)$ of the portfolio as follows:

$$
\begin{aligned}
& m=\ln (1+\mu)-\left(\frac{s_{2}}{2}\right) \\
& s=\sqrt{\ln \left[1+\left(\frac{\sigma}{1+\mu}\right)^{2}\right]}
\end{aligned}
$$

where $\ln$ is the natural logarithm function.

Given the logarithm parameters of a portfolio ( $m$ and $s$ ), a time horizon $(n)$, and the $z$-score of a percentile $(z)$, the percentile of the geometric mean return for an asset $i$ is calculated as follows:

$$
R_{i}=\exp \left(m_{i}+Z \times\left(\frac{s_{i}}{\sqrt{n}}\right)\right)-1
$$

where $R_{i}$ is percentile of the geometric mean return of asset $i ; m_{i}$ is expected value of natural logarithm of the return relative of asset $i$; $s_{i}$ is standard deviation of natural logarithm of the return relative of asset $i ; z$ is the z-score of the percentile; and $n$ is investment horizon.

Using this equation, it is possible to calculate the various percentiles of the geometric mean return over various time horizons. The rate of return for the $50^{\text {th }}$ percentile of each asset is used as the projected return for portfolio performance of the retirement wealth in the current study (Table 1). Data for historical rates of return from the Stocks, Bonds, Bills and Inflation Yearbook published by Ibbotson Associates $^{29}$ are used to provide information on the mean and variance of the real rate of return for specific asset categories. The 2005 Yearbook provides historical return data from 1 January 1926 to 31 December 2004 for various investment categories such as stocks, corporate bonds, government bonds and real estate. 


\section{Findings and discussion}

The projected retirement income replacement rate $(P R)$ represents the extent of the possibility to maintain the permanent income standard of individual households during retirement. For analysis, the total sample is divided into five sub-groups by the projected replacement rate: $P R<50$ per cent; 50 per cent $\leqslant P R<70$ per cent; 70 per cent $\leqslant P R<85$ per cent; 85 per cent $\leqslant P R<100$ per cent; and $P R \geqslant 100$ per cent.

\section{Analysis of variance}

About 39 per cent of the households have a projected replacement rate 100 per cent or above, suggesting that they are the only ones who are able to maintain the level of living equivalent to their permanent income or above during retirement (Table 2). Strictly speaking, the other 61 per cent are not able to maintain their permanent income standard in retirement even if their retirement portfolios achieve an average rate of return in the future. This number is quite comparable with some recent previous studies (e.g., Engen et al. ${ }^{11}$ : 60.5 per cent for the HRS and 66 per cent for the SCF; Haveman et al. ${ }^{14}: 60$ per cent). If the target is lowered to 85 (70) per cent of the projected replacement rate, about 46 (56) per cent of the pre-retired households are able to maintain it during retirement. In other words, at least 44 per cent will be "at risk" of being able to maintain 70 per cent of their permanent income standard in retirement.

The mean (median) retirement wealth is US\$1,782,306 (US\$630,265), and it increases with the projected replacement rate to US\$4,630,197 for those with a projected replacement rate $\geqslant 100$ per cent. The mean DBW also increases as the projected replacement rate increases. Those with a projected replacement rate $<50$ per cent have the largest mean (US\$404,052) of SSW among the five groups. It is plausible that those with low replacement rate might receive their retirement income mainly from Social Security since they have significantly low income from pensions, financial assets and non-financial assets. The mean FW is the largest for those with a projected replacement rate $\geqslant 100$ per cent and the smallest for those with $<50$ per cent. The mean NFW increases from US $\$ 68,687$ for those with a projected replacement rate $<50$ per cent to US\$2,731,195 for those with a projected replacement rate $\geqslant 100$ per cent. The mean share of each wealth component among the total retirement wealth is also presented in Table 2. On the whole, the mean shares of DBW, DCW and NFW increases, while those of SSW decreases with the projected replacement rate.

The mean (median) replacement ratio and that of each wealth component $\left(P R W_{i}\right)$ are presented in Table 3 . The mean and median projected replacement rate are about 117 and 67 per cent for the total sample, and on average SSW and NFW replace 42 and 41 per cent of the permanent income, respectively. Comparing the replacement ratio of each wealth component by the five groups, all ratios consistently increase with the projected replacement rate except for $P R W_{3}$ (Social Security replacement ratio). For all four groups with $<100$ per cent of the projected replacement rate, the mean Social Security replacement ratio $\left(P R W_{3}\right)$ is the largest among the five components' $P R W_{i}$. The NFW has the largest replacement ratio (146 per cent) for those with $\geqslant 100$ per cent of the projected replacement rate. The next largest one is $P R W_{2}$ (DCW's replacement ratio) for all groups excluding those with the highest replacement rate 


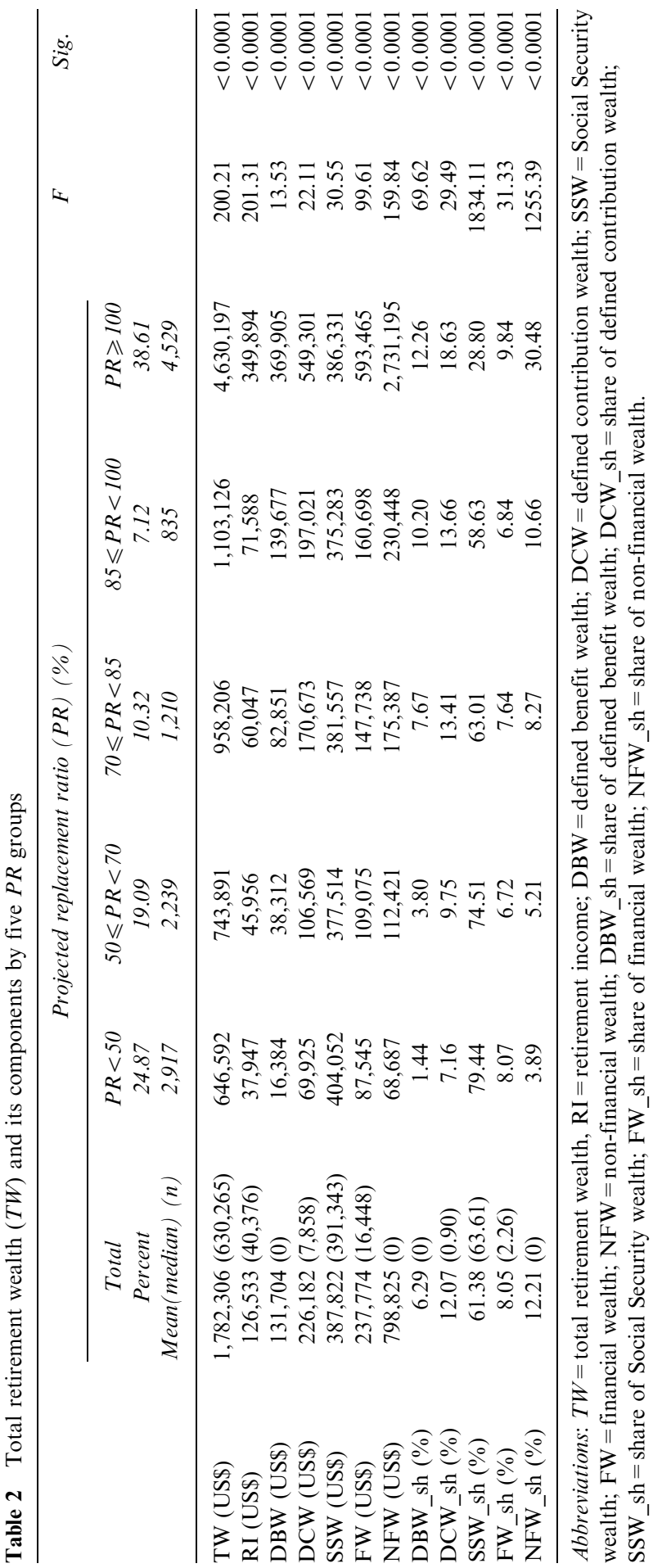


Table 3 Projected replacement ratio $\left(P R\right.$ and $\left.P R W_{i}\right)$ by five $P R$ groups

\begin{tabular}{|c|c|c|c|c|c|c|c|c|}
\hline & \multicolumn{6}{|c|}{ Projected replacement ratio $(P R)(\%)$} & \multirow[t]{2}{*}{$F$} & \multirow[t]{2}{*}{ Sig. } \\
\hline & $\begin{array}{c}\text { Total } \\
\text { Percent } \\
\text { Mean (median) }(n)\end{array}$ & $\begin{array}{c}P R<50 \\
24.87 \\
2,917\end{array}$ & $\begin{array}{c}50 \leqslant P R<70 \\
19.09 \\
2,239\end{array}$ & $\begin{array}{c}70 \leqslant P R<85 \\
10.32 \\
1,210\end{array}$ & $\begin{array}{c}85 \leqslant P R<100 \\
7.12 \\
835\end{array}$ & $\begin{array}{c}P R \geqslant 100 \\
38.61 \\
4,529\end{array}$ & & \\
\hline PR $(\%)$ & $117.17(66.71)$ & 37.12 & 59.51 & 76.69 & 91.98 & 287.98 & 43.00 & $<0.0001$ \\
\hline $\mathrm{PRW}_{1}(\%)$ & $10.51(0.00)$ & 0.61 & 2.33 & 5.96 & 9.46 & 31.79 & 23.38 & $<0.0001$ \\
\hline $\mathrm{PRW}_{2}(\%)$ & $14.29(0.64)$ & 2.66 & 5.83 & 10.29 & 12.61 & 37.70 & 118.00 & $<0.0001$ \\
\hline $\mathrm{PRW}_{3}(\%)$ & $41.85(38.47)$ & 29.71 & 44.11 & 48.18 & 53.72 & 46.67 & 188.59 & $<0.0001$ \\
\hline $\mathrm{PRW}_{4}(\%)$ & $9.83(1.54)$ & 2.76 & 4.05 & 5.85 & 6.29 & 26.17 & 94.94 & $<0.0001$ \\
\hline $\mathrm{PRW}_{5}(\%)$ & $40.69(0.00)$ & 1.39 & 3.18 & 6.41 & 9.91 & 145.64 & 31.01 & $<0.0001$ \\
\hline
\end{tabular}

Abbreviations: $\mathrm{PRW}_{1}=P R$ of defined benefit wealth (DBW); $\mathrm{PRW}_{2}=P R$ of defined contribution wealth $(\mathrm{DCW}) ; \mathrm{PRW}_{3}=P R$ of Social Security wealth (SSW); $\mathrm{PRW}_{4}=P R$ of financial wealth $(\mathrm{FW}) ; \mathrm{PRW}_{5}=P R$ of non-financial wealth (NFW).

$(P R \geqslant 100$ per cent) and the lowest replacement rate $(P R<50$ per cent $)$. Those with $\geqslant 100$ per cent of the projected replacement rate have 47 per cent of the SSW replacement ratio and 38 per cent of the DCW replacement ratio, respectively.

Results from the Analysis of Variance (ANOVA) on demographic and financial factors by the five replacement ratio groups are provided in Table 4. Planned retirement age increases with the projected replacement rate as shown. Mean planned retirement age is 65.5 years for those with $\geqslant 100$ per cent and 61 for those with $<50$ per cent of the projected replacement rate. The highest replacement rate group $(P R \geqslant 100$ per cent) has the highest permanent income (US\$114,049) and those with a projected replacement rate of 50-70 per cent have the lowest permanent income (US\$77,252). About 62 per cent of those with $<50$ per cent of the projected replacement rate are married households, and 82 per cent of those with $\geqslant 100$ per cent of the projected replacement rate are white. The proportion of households with less than a high school education is 15 per cent for those with a projected replacement rate of 85-100 per cent, and about 50 per cent of those with a projected replacement rate $\geqslant 100$ per cent have college or advanced degrees. Among the highest replacement ratio groups $(P R \geqslant 100$ per cent), about 29 per cent are self-employed and 33 per cent are taking a high financial risk in savings and investment decisions.

Equity and bond proportions of non-housing assets are the highest for those with a projected replacement rate $\geqslant 100$ per cent (15.4 and 10.2 per cent, respectively), and the cash equivalents proportion at 12 per cent is the lowest in this group among the five groups. Those with a projected replacement rate of $85-100$ per cent and $<50$ per cent have the lowest equity proportion ( 8.6 and 8.8 per cent, respectively). The equity and bond shares are the highest, while the cash share is the lowest for the projected replacement rate $\geqslant 100$ per cent, but the increasing or decreasing pattern by the five groups is not clearly identified here.

\section{Determinants of projected replacement ratio}

The multivariate ordinary least squares regression analysis is performed to estimate the effect of each independent variable while simultaneously controlling for effects of 


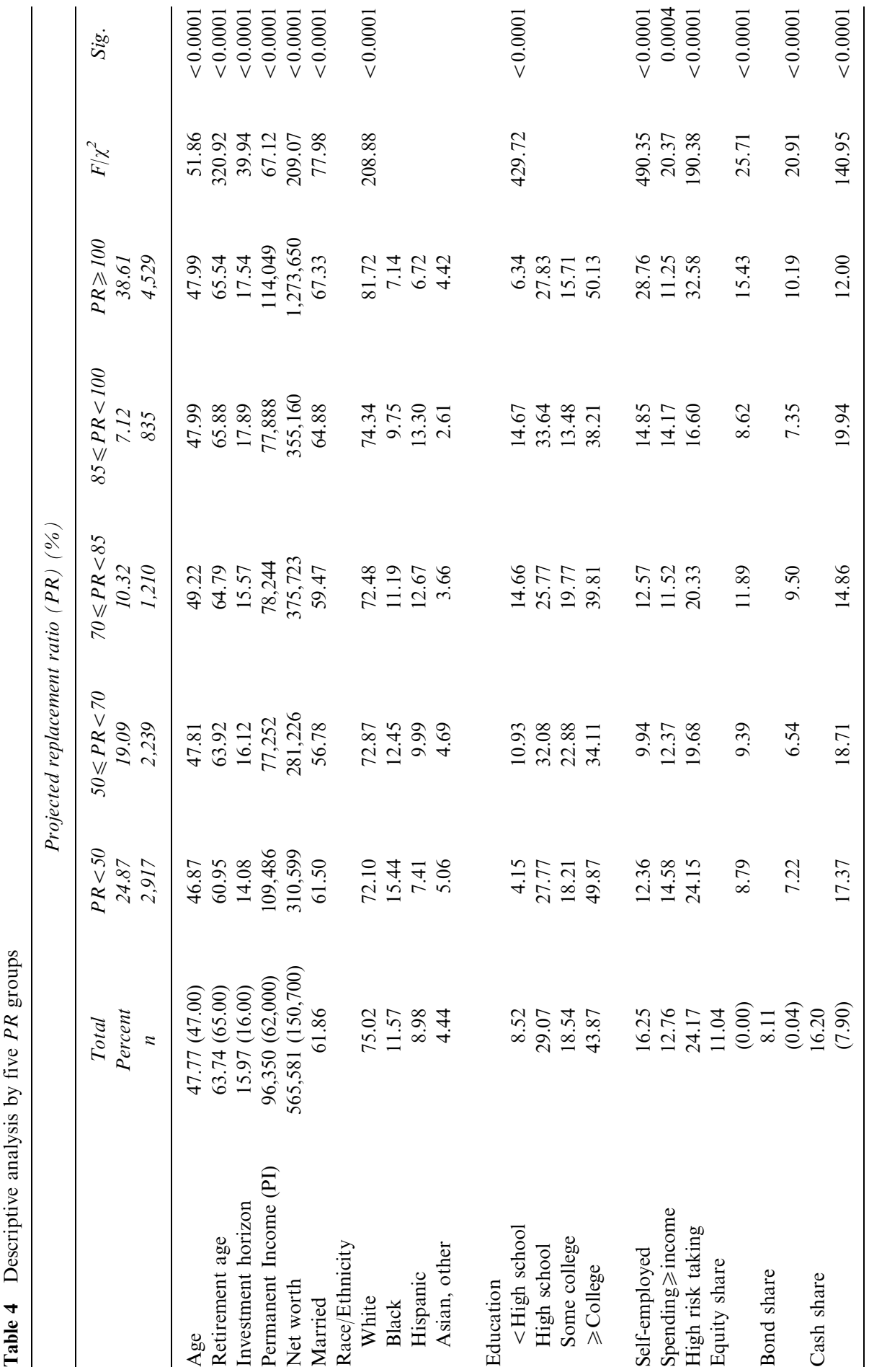


Table 5 Least squares regression of $P R$

\begin{tabular}{|c|c|c|c|c|}
\hline Variable & & Estimate & Std. error & P-value \\
\hline Intercept & & -1.4397 & 0.0426 & $<0.0001^{* * *}$ \\
\hline Married & & 0.0106 & 0.0180 & 0.5559 \\
\hline Education & $(\geqslant$ College $)$ & & & \\
\hline Less than high school & & -0.0846 & 0.0361 & $0.0190 *$ \\
\hline High school graduate & & 0.0082 & 0.0210 & 0.6960 \\
\hline Some college & & 0.0418 & 0.0231 & 0.0707 \\
\hline Race/ethnicity & (White) & & & \\
\hline Black & & -0.1037 & 0.0297 & $0.0005 * * *$ \\
\hline Hispanic & & -0.0378 & 0.0328 & 0.2486 \\
\hline Asian, other & & 0.0566 & 0.0375 & 0.1318 \\
\hline Self-employed & & 0.3512 & 0.0184 & $<0.0001^{* * *}$ \\
\hline Log of net worth & & 0.0716 & 0.0024 & $<0.0001^{* * *}$ \\
\hline Retirement age (years) & (61 or earlier) & & & \\
\hline $62-65$ & & 0.1425 & 0.0198 & $<0.0001 * * *$ \\
\hline 66 or up & & 0.5508 & 0.0205 & $<0.0001 * * *$ \\
\hline Investment horizon & & 0.0242 & 0.0010 & $<0.0001 * * *$ \\
\hline Equity share & & -0.0073 & 0.0012 & $<0.0001 * * *$ \\
\hline Equity share $^{2}$ & & 0.0001 & 0.0000 & $<0.0001^{* * *}$ \\
\hline Bond share & & -0.0051 & 0.0008 & $<0.0001 * * *$ \\
\hline Bond share $^{2}$ & & 0.0001 & 0.0000 & $<0.0001 * * *$ \\
\hline Cash share & & -0.0281 & 0.0011 & $<0.0001 * * *$ \\
\hline Cash share $^{2}$ & & 0.0003 & 0.0000 & $<0.0001$ \\
\hline Spending $\geqslant$ income & & -0.0144 & 0.0261 & 0.5793 \\
\hline High risk-taking & & 0.1567 & 0.0172 & $<0.0001^{* * *}$ \\
\hline$F$ & 304.83 & & $P$-value & $<0.0001 * * *$ \\
\hline$R^{2}$ & 0.3431 & & & \\
\hline
\end{tabular}

Note: *:P-value $\leqslant 0.5 ; * *: P$-value $\leqslant 0.01 ; * * *: P$-value $\leqslant 0.001$.

all the other independent variables. ${ }^{32}$ The projected replacement rate captures the annuitised amount of the total retirement wealth relative to permanent income; thus, it measures the extent of the adequacy of retirement wealth in each household. The projected replacement rate prediction equation explains approximately 34 per cent of the variance (Table 5).

Households without a high school education have significantly lower projected replacement rate than otherwise similar households with a college or advanced degree. Being black relative to white decreases the projected replacement rate significantly, and self-employed households have significantly higher projected replacement rate than otherwise similar non-self-employed households. Log of net worth is also positively associated with the projected replacement rate. Planned retirement age has a large effect on the predicted replacement rate. Those who plan to retire between the ages of 62 and 65 years, and those who plan to retire at the age of 66 years or later have significantly higher projected replacement rate than otherwise similar households

${ }^{32}$ Explanatory variables are selected based on previous studies discussed in the literature review section. 
who plan to retire before the age of 62 years. Particularly, those who plan to retire at the age of 66 years or later have a much higher projected replacement rate than those who plan to retire between the ages of 62 and 65 years. The predicted replacement rate also increases with the investment horizon. That is, those with a longer investment horizon have significantly higher projected replacement rate compared with those with a shorter investment horizon. Holding other factors constant, more risk tolerant households have a higher projected replacement rate than otherwise similar households who are not risk tolerant. Equity, bonds, cash equivalent shares of non-housing assets and their squared are all significantly related to the predicted replacement rate when other variables are held constant. All of these three shares have a curvilinear relationship with the projected replacement rate. To provide some idea of the magnitude of the effect of each share, predicted replacement rates are simulated based on the regression model. ${ }^{33}$ The predicted replacement rates are in the range of 58-78 per cent, 59-77 per cent and 41-87 per cent according to the shares of equity, bonds and cash, respectively. That is, the predicted replacement rate seems to be more stable with respect to the changes in the bond and equity shares, while the replacement rate is more volatile with the changes in the cash shares. On the whole, having an equity or bond provides a higher replacement rate than cash equivalents if holding the same share.

\section{Conclusion}

The current study projects the retirement income replacement ratio from accumulated wealth at retirement and the permanent income of individual households. The projected replacement ratio $(P R)$ in this study measures the extent of maintaining the households' permanent income living standard into retirement. Furthermore, it can represent the adequacy of retirement income under the smoothing consumption of the life cycle model. This study estimates that the total retirement wealth of pre-retired households is expected to replace about 67 per cent (median) of their permanent income (Table 3). Thus, this study confirms that the well-known rule of the 70 per cent replacement ratio frequently used in financial planning ${ }^{34}$ is quite reasonable as an average, but it is also found to be highly volatile depending on the households' characteristics. On the other hand, this study projects that at most 61 per cent $(P R<100$ per cent) and at minimum 44 per cent $(P R<70$ per cent $)$ of U.S. households headed by workers aged 35-70 years will be "at risk" of being financially unprepared for their retirement, even if investments achieve an average rate of return in the future (Table 2). The estimates presented in this study are based on the current rules of Social Security and pension plans and ignore the effect of income taxes, so the situation could be worse than presented. In addition, the proportion of households unable to maintain the permanent income standards in retirement becomes larger because of longevity and rising health-care costs. ${ }^{35}$ Thus, these retirees will be forced to reduce their living standards in retirement.

\footnotetext{
${ }^{33}$ Simulation results are available from the author.

${ }^{34}$ Booth (2004).

${ }^{35}$ Skinner (2007).
} 
One of the contributions of this study is including the equity, bond and cash shares in the non-housing assets, and using them as explanatory variables for the projected replacement ratio. The proportions of non-housing assets held in equity, bonds and cash equivalents are found to be significant factors affecting the replacement ratio. The ANOVA results show that those with a projected replacement ratio $\geqslant 100$ per cent have the largest equity share (15.4 per cent), bond share (10.2 per cent) and the smallest cash share (12 per cent) among the five replacement ratio groups (Table 3). In addition, the group with the lowest replacement ratio of $<50$ per cent has only 8.8 per cent of equity share. However, when other variables are controlled, a curvilinear relationship between each three shares and the replacement ratio is confirmed (Table 5). Moreover, in the same share level, holding equity or bond results in higher replacement ratio compared with holding cash equivalents. In addition, households taking a high financial risk in savings and investments have a higher replacement ratio than otherwise similar households not taking high financial risks. Thus, as previous studies emphasised the importance of asset allocation for pension plans, ${ }^{36}$ this evidence of higher replacement ratio by more aggressive asset allocation could be used to encourage stock investment within the retirement savings programs.

On the other hand, planned retirement age has a large effect on the predicted replacement rate even after controlling for other factors (Table 5). Those who plan to retire between the ages of 62 and 65 years and those who plan to retire at the age of 66 years or later have a significantly higher replacement rate than otherwise similar households who plan to retire before the age of 62 years. Particularly, the effect of delaying retirement until the age of 66 years or later is very large. Besides, those with a longer investment horizon have higher replacement rate. Both later retirement and a longer investment horizon provide more years to accumulate retirement wealth and increase the probability of receiving full benefits from Social Security and pension plans, which increase the replacement ratio. Therefore, financial educators, counselors and planners should assist clients in choosing the appropriate retirement ages by evaluating retirement resources and estimating retirement needs. Particularly, clients who plan to retire at relatively young ages (earlier than the age of 62 years) should be helped in developing reasonable saving plans.

\section{References}

Aguiar, M. and Hurst, E. (2005) 'Consumption versus expenditure', Journal of Political Economy 113(5): 919-948.

Aon Consulting (2001) Replacement Ratio Study, Chicago: Aon Consulting.

apRoberts, L. (2009) 'Trends in the retirement system of the United States', The Geneva Papers on Risk and Insurance - Issues and Practice 34(4): 618-630.

Bernheim, B.D. (1997) 'The adequacy of personal retirement saving: Issues and options', in D.A. Wise (ed.) Facing the Age Wave, Publication No 440. Stanford, CA: Hoover Institution Press, pp. 30-56.

Bernheim, B.D., Skinner, J. and Weinberg, S. (2001) 'What accounts for the variation in retirement wealth among U.S. Households?' American Economic Review 91(4): 832-857.

\footnotetext{
${ }^{36}$ For example, Yang and Huang (2009), Blake et al. (2007).
} 
Blake, D., Cairns, A. and Dowd, K. (2007) 'The impact of occupation and gender on pensions from defined contribution plans', The Geneva Papers on Risk and Insurance - Issues and Practice 32(4): 458-482.

Booth, L. (2004) 'Formulating retirement targets and the impact of time horizon on asset allocation', Financial Services Review 13: 1-17.

Boskin, M.J. and Shoven, J.B. (1987) 'Concept and measures of earnings replacement rates during retirement', In Z. Bodie J. Shoven and D. Wise (eds.) Pensions and Retirement in the United States, Chicago: University of Chicago Press for NBER, pp. 113-141.

Butrica, B.A, Smith, K.E. and Iams, H. (2003) It's all relative: Understanding the retirement prospects of baby-boomers, CRR Working Paper 2003-21, November, Center for Retirement Research at Boston College, Chestnut Hill, MA.

Crow, E.L. and Shimizu, K. (1988) Lognormal Distribution, New York: Marcel Dekker.

Engen, E.M., Gale, W.G., Uccello, C.E., Carroll, C.D. and Laibson, D.I. (2000) 'The adequacy of household saving', Brookings Papers on Economic Activity 2: 65-187.

Gustman, A.L. and Steinmeier, T.L. (1998) Effects of pensions on saving: Analysis with data from the Health and Retirement Study, NBER Working Paper 6681.

Hatcher, C.B. (1998) 'A model of desired wealth at retirement', Financial Counseling and Planning 8(1): $57-64$.

Haveman, R., Holden, K., Wolfe, B. and Romanov, A. (2007) 'Assessing the maintenance of savings sufficiency over the first decade of retirement', International Tax and Public Finance 14: 481-502.

Haveman, R., Holden, K., Wolfe, B. and Sherlund, S. (2006) 'Do newly retired workers in the U.S. have sufficient resources to maintain well-being?' Economic Inquiry 44(2): 249-264.

Ibbotson Associates (2005) Stocks, Bonds, Bills, and Inflation Yearbook, Chicago: Ibbotson Associates.

Internal Revenue Services (2003) 'General Rule for Pensions and Annuities', Publication 939 from http:// www.irs.gov/publications/p939/index.html, accessed 20 October 2008.

Kennickell, A.B. (1995) Saving and permanent income: Evidence from the 1992 SCF, Board of Governors of the Federal Reserve System, Working Paper.

Lusardi, A. and Mitchell, O.S. (2007) 'Baby Boomer retirement security: The roles of planning, financial literacy, and housing wealth', Journal of Monetary Economics 54(1): 205-224.

Mitchell, O.S. and Moore, J.F. (1998) 'Can Americans afford to retire? New evidence on retirement saving adequacy', Journal of Risk and Insurance 65(3): 371-400.

Modigliani, F. and Brumberg, R. (1954) 'Utility analysis and the consumption function: an interpretation of cross-section data', in K.K. Kurihara (ed.) Post Keynesian Economics, New Brunswick, NJ: Rutgers University Press, pp. 388-446.

Moore, J.F. and Mitchell, O.S. (2000) 'Projected retirement wealth and savings adequacy in forecasting retirement needs and retirement wealth', In O. Mitchell, B. Hammond and A. Rappaport (eds.) Forecasting Retirement Needs and Retirement Wealth, Philadelphia, PA: University of Philadelphia Press, pp. 68-94.

Munnell, A.H., Webb, A. and Golub-Sass, F. (2007) Is There Really a Retirement Savings Crisis? An NRRI analysis, Issue in Brief, pp. 7-11, Chestnut Hill, MA: Center for Retirement Research at Boston College.

Scholz, J.K., Sheshadri, A. and Khitatrakun, S. (2006) 'Are Americans saving “optimally” for retirement?' Journal of Political Economy 114(4): 607-643.

Skinner, J. (2007) 'Are you sure you're saving enough for retirement?' Journal of Economic Perspectives 21: $59-80$.

Smith, K.E. (2003) How will recent patterns of earnings inequality affect future retirement incomes? Final Report for AARP, The Urban Institute, Washington, DC.

Social Security Administration (2005) 'Annual Statistical Supplement, 2004 to the Social Security Bulletin', SSA Publication no.13-11827, Social Security Administration, Office of Policy, Office of Research, Evaluation and Statistics, Washington, DC.

Thorley, S.R. (1995) 'The time-diversification controversy', Financial Analyst Journal 51(3): 68-76.

Valdez, E.A. and Chernih, A. (2003) 'On retirement income replacement ratios', Faculty of Commerce \& Economics, School of Actuarial Studies, The University of New South Wales, Sydney, Australia, mimeo.

Venti, S. and Wise, D.A. (1990) 'But they don't want to reduce housing equity', In: D. Wise (ed.) Issues in the Economics of Aging, Chicago: University of Chicago Press, pp. 13-32.

Venti, S. and Wise, D.A. (1991) 'Aging and the income value of housing wealth', Journal of Public Economics 44: 371-395. 
Wolff, E.N. (2002) Retirement Insecurity: The Income Shortfalls Awaiting the Soon-to-retire, Washington, DC: Economic Policy Institute.

Wolff, E.N. (2006) The adequacy of retirement resources among the soon-to-retire, 1983-2001, Levy Economics Institute Working Paper no. 472.

Yang, S.S. and Huang, H. (2009) 'The impact of longevity risk on the optimal contribution rate and asset allocation for defined contribution pension plans', The Geneva Papers on Risk and Insurance — Issues and Practice 34(4): 660-681.

Yuh, Y., Montalto, C. and Hanna, S.D. (1998) 'Are Americans prepared for retirement?' Financial Counseling and Planning 9(1): 1-12.

\begin{abstract}
About the Author
Yoonkyung Yuth is an Associate Professor in the Department of Business Administration at Ewha Womans University in Seoul, Korea. She has won several research awards for research publications in the U.S. and had some research featured in an article in the New York Times, and other newspapers. She has published in Financial Service Review, Journal of Consumer Affairs, Financial Counseling and Planning, Family and Consumer Sciences Research Journal, and Applied Economics (forthcoming).
\end{abstract}

